\title{
ĐẶC ĐIỂM QUẬNG HÓA VÀ KHOÁNG VẬT CÁC MỎ KẼM CHİ KHU VỰC LÀNG HÍCH
}

\author{
PHẠM NGỌC CẨ, TRẦ TUẤN ANH, TRẦN TRỌNG HÒA, PHẠM THỊ DUNG, \\ NGÔ THI PHUỰNG, TRÂN QUỐC HÙNG, BÙI ẤN NIÊN, NGUYẼ̃N VIẾT Ý, TRẦN VĂN HIẾU
}

\author{
E-mail: phamngoccan87255@yahoo.com \\ Viện Địa chất - Viện khoa học và Công nghệ Việt Nam
}

Ngày nhận bài : 05-9-2010

\section{Mở đầu}

Khu mỏ Làng Hích được người Pháp phát hiện từ năm 1905 và đưa vào khai thác từ năm 1913 cho đến năm 1928. Trong giai đoạn này, việc khai thác quặng sulfur chủ yếu theo hình thức khai đào trên mực nước ngầm. Các tài liệu điều tra, đánh giá trữ lượng và chất lượng, các tài liệu về các công trình khai đào của khu mỏ hiện nay không còn, chỉ còn lại một số báo cáo về khoáng sản và một số tờ bản đồ mỏ.

Hiện nay, xí nghiệp Kẽm-chì Làng Hích (Công ty TNHH Nhà nước một thành viên kim loại màu Thái Nguyên) với sáu điểm khai thác (Metis (khu đông và khu tây), Mỏ Ba (lò $1 \mathrm{~A}$ và lò $1 \mathrm{~B})$, Hang Chùa và khu Bắc Lâu) bao quát trên 280 ha thuộc Huyện Đồng Hỷ, tỉnh Thái Nguyên, mỗi năm khai thác được trên 20.000 tấn quặng các loại, trong đó có từ 18.000 đến 20.000 tấn quặng sulfur, khoảng 4.000 tấn quặng oxit.

Do nhu cầu đánh giá lại khu mỏ phục vụ khai thác và phục vụ công tác thành lập bản đồ địa chất và khoáng sản, đã có nhiều tài liệu mô tả đặc điểm địa chất khu mỏ Làng Hích nhưng vẫn chưa có tài liệu nào nêu ra được đặc điểm quặng hóa và khoáng vật của khu mỏ này. Dưới đây là một số kết quả nghiên cứu mới nhất của chúng tôi từ đề tài KC.08.24/06-10.

\section{2. Đặc điểm địa chất mỏ kẽm - chì khu vực Làng Hích}

Khu mỏ kẽm-chì Làng Hích nằm trên địa bàn xã Tân Long, cách trung tâm huyện Đồng Hỷ chừng $25 \mathrm{~km}$. Tại đây phát triển các thành tạo carbonat, lục nguyên, lục nguyên xen carbonat tuổi Paleozoi thuộc nếp nồi Thần Sa. Các tụ khoáng và điểm quặng hóa thường phân bố theo các đới dập vỡ của đá vôi thuộc hệ tầng Mia Lé $\left(\mathrm{D}_{1} m l\right)$ và hệ tầng Bắc
Sơn (C-P bs) tạo thành các thân quặng dạng mạch, dạng trao đổi thay thế. Mỗi tụ khoáng thường có hai đến nhiều thân quặng, kéo dài $25-300 \mathrm{~m}$, dày $1-4 \mathrm{~m}$, duy trì xuống sâu có khi đến $100 \mathrm{~m}$.

Sáu điểm khai thác khu mỏ Làng Hích tập trung vào ba khu vực chính là: Mỏ $\mathrm{Ba}$, Metis và Bắc Lâu. $\mathrm{Ba}$ khu vực này nằm kề nhau, có cấu tạo địa chất khá giống nhau. Tuy nhiên tại Mỏ $\mathrm{Ba}$ và Metis quặng chủ yếu là sunfua, còn tại Bắc Lâu chủ yếu là quặng thứ sinh.

\subsection{Khu vục Mỏ Ba}

Mỏ Ba là mỏ có trữ lượng quan trọng nhất của toàn mỏ Làng Hích. Quặng hóa phân bố trong đá vôi, vôi silic, đá vôi dolomit thuộc hệ tầng Bắc Sơn, gần tiếp xúc với hệ tầng Mia Lé (hình 1).

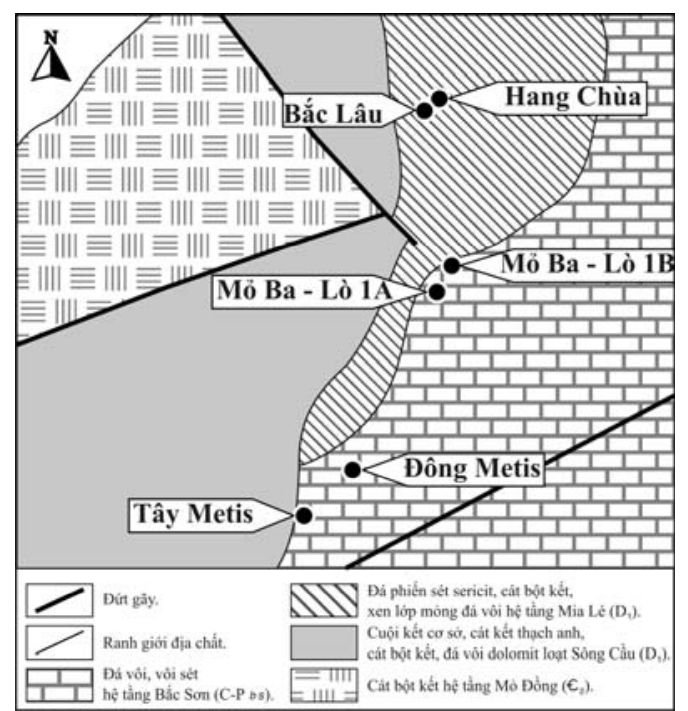

Hình 1. Sơ đồ địa chất các mỏ kẽm-chì khu vực Làng Hích 
Mỏ gồm nhiều thân quặng dài từ vài chục mét đến gần $300 \mathrm{~m}$, dày từ $1-2 \mathrm{~m}$ đến $35 \mathrm{~m}$, sâu $100 \mathrm{~m}$. Căn cứ vào hình dạng thân quặng và mối quan hệ với các thành tạo vây quanh có thể phân thành 4 loại thân quặng: a) Thân quặng có hình dạng không đều đặn, liên quan với các đứt gãy kiến tạo (hướng $\mathrm{TB}\left(330^{\circ}\right)$ cắm về $\mathrm{TN}$ ở phần đông và Tây lò $1 \mathrm{~B}$; hướng $\mathrm{ĐB}\left(30^{\circ}\right)$ cắm về $\mathrm{TB}\left(30-40^{\circ}\right)$; b) Các thân quặng nghiêng, đôi khi có dạng lớp. Khoáng hóa xuất hiện giữa các đứt gãy; c) Các mạch nghiêng liên quan với các đứt gãy kiến tạo (Các mạch nghiêng hướng đông bắc $\left(30^{\circ}\right)$, cắm về đông nam với góc dốc $70^{\circ}$; hướng tây bắc $\left(320^{\circ}\right)$, cắm về đông bắc $\left(0-80^{\circ}\right)$ như ở lò 11$)$; d) Các mạch canxit hơi nghiêng cùng với một lượng quặng xâm tán nhỏ.

\subsection{Khu vyec Metis}

Các thân quặng của mỏ phân bố trong vùng phát triển đá vôi, vôi sét, vôi silic, vôi tái kết tinh thuộc hệ tầng Bắc Sơn, gần tiếp xúc với loạt sông Cầu $\mathrm{D}_{1} s c$ ). Mỏ có hai kiểu thân quặng chính : Các thân quặng dạng mạch rất dốc đứng lấp đầy và các thân quặng biến chất trao đổi không đều. Ngoài ra, trong khu vực còn có quặng eluvi - deluvi bị oxy hóa. Tất cả các khoáng hóa thuộc khu Làng Hích đều liên quan trực tiếp với đứt gãy chính Làng Hích có phương Đông Bắc - Đông $\left(60^{\circ}\right)$, cắm dốc về phía Nam, hoặc nằm ngay trên nóc, trong cacbonat tiếp xúc với cát kết phân phiến.

\subsection{Khu vục Bắc Lâu}

Khoáng hóa khu vực Bắc Lâu nằm ở tiếp xúc giữa các đá cacbonat và cát kết phân phiến. Thành phần quặng ở đây gồm cả quặng sunfua và oxit. Đặc điểm quặng sunfua tương tự như khoáng hóa của đứt gãy Đông và Mỏ $\mathrm{Ba}$. Quặng oxy hóa nằm trên các sườn (deluvi) có chiều dày khoảng 1-2m, đôi khi dạng lấp đầy trong các hốc đá vôi.

Nhìn chung, quặng hóa chì kẽm trong khu vực Làng Hích thường tập trung dọc theo các đứt gãy phương ĐB-TN. Thành phần chủ yếu của quặng là galenit, sphalerit, pyrit. Ở một số tụ khoáng, quặng bị oxy hóa tạo thành các thân quặng thứ sinh gồm chủ yếu là cerusit, anglesit, smithsonit, calamin. Hàm lượng kẽm thường đạt trên dưới $10 \%$. Ngoài chì, kẽm, trong quặng còn có lượng cadmi khá cao.

\section{3. Đặc điểm thành phần khoáng vật khu mỏ Làng Hích}

\subsection{Tổ hợp khoáng vật quặng}

Quặng kẽm chì khu vực Làng Hích có thành phần khoáng vật chủ yếu là sphalerit, galenit, pyrit và các khoáng vật thứ yếu khác như arsenopyrit, pyrotin (ảnh 1).
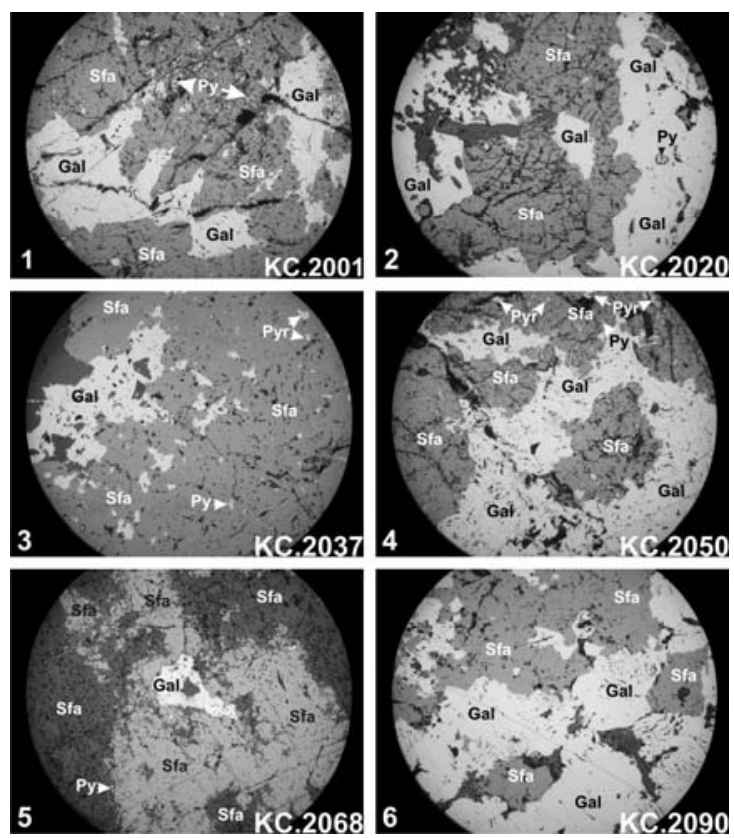

Anh 1. Ảnh chụp mẫu khoáng tướng một số mẫu quặng khu mỏ Làng Hích, 1 - Tây Metis; 2 - Đông Metis; 3 - Hang Chùa; 4 - Bắc Lâu; 5 Mỏ 3 lò 1B; 6 - Mỏ 3 lò 1A. Sfa - Sphalerit; Gal Galenit; Py - Pyrit; Pyr - Pyrotin

Sphalerit chiếm phần lớn, màu nâu sáng, màu nâu sẫm và màu xám sáng có kích thước từ $0,0 \mathrm{~m}$ đến vài milimet. Chúng phân bố thành quặng đặc xít phân bố trong các khe nứt tách của đá gốc, ngoài ra còn gặp chúng dưới dạng các đám rời rạc mà ở đó thường bị các tấm galenit chen lấp vào; thỉnh thoảng còn thấy các bao thể pyrotin là sản phẩm của quá trình phân rã dung dịch cứng. Trong các mẫu khoáng tướng, sphalerit chiếm 55-95\% (trung bình72,5\%). Còn trong các mẫu phân tích trọng sa nhân tạo, sphalerit chiếm 40-95\% (trung bình $73,125 \%$ ).

Galenit số lượng không nhiều, tạo thành các tập hợp, hoặc các hạt biệt lập mọc xen với sphalerit và pyrit. Trong các mẫu khoáng tướng, Galenit có thành phần $1-20 \%$ (trung bình $10,38 \%$ ), đôi khi lên đến 45-50\%. Galenit gặp ít trong các mẫu trọng sa. Không quan sát thấy hiện tượng biến đổi khoáng vật, chỉ có sự gặm mòn ở ranh giới tiếp xúc giữa sphalerit và galenit.

Pyrit ít gặp, thường là các hạt nhỏ, hoặc các hạt trung bình bị vỡ vụn, có dấu hiệu bị gặm mòn. Pyrit 
chiếm $1-3 \%$ trong các mẫu khoáng tướng và rất ít trong các mẫu trọng sa nhân tạo. Đôi chỗ pyrit bị markazit hóa.

Pyrotin có dạng tha hình và nhiều trường hợp bị dập vỡ tạo nhiều hạt nhỏ bị gặm mòn xung quanh có dạng hơi tròn cạnh và kéo dài theo chuỗi nhồi theo các khe nứt của đá mẹ.

Arsenopyrit có tinh thể dạng hình bình hành hoặc bán thoi, có độ mài nhẵn tốt. Chúng thường tạo thành các dải phân bố len lỏi theo kẽ hở của sphalerit hoặc đôi khi tụ tập thành đám nhỏ độc lập.

\subsection{Các khoáng vật phụ đi kèm}

Khoáng vật phi quặng chủ yếu là canxit màu trắng, tồn tại dưới dạng thấu kính không đều, dài vài chục mét, dày khoảng $1 \mathrm{~m}$. Dolomit cũng nằm trong các mạch quặng nhưng chỉ chiếm phần thứ yếu. Thạch anh chỉ tạo thành những vi mạch nhỏ nằm trong canxit. Ngoài ra còn gặp một ít granat.

Trong khu vực này cũng có quặng $\mathrm{Pb}$ và $\mathrm{Zn}$ deluvi thứ sinh như smithsonit, calamin, hydrozincit, octavit, cerusit, anglesit, covelit và limonit.

Khoáng vật thứ sinh phổ biến nhất là smithsonit có màu nâu hạt dẻ vàng, dạng khối, thường đi kèm với limonit. Đôi khi smithsonit tạo thành các tập hợp hình bầu dục, màu xám phớt xanh hoặc nâu sẫm đến trắng, hay các tinh thể phớt lục trong các lỗ hổng quặng oxy hóa. Calamin xuất hiện với lượng ít hơn, dạng khối màu sẫm, là những tinh thể trong suốt nằm trong các lỗ hổng quặng bị oxy hóa.

Các khoáng vật thứ sinh của chì khá hiếm, cerusit phổ biến hơn, tạo thành những tinh thể nhỏ $\sim 1 \mathrm{~mm}$ dạng tấm màu nâu vàng nhạt hoặc trắng nằm trong những lỗ hổng và khe nứt của quặng oxy hóa hoặc những tập hợp hạt mịn nâu sẫm gần như đen, liên quan chặt chẽ với galenit.

Ngoài ra còn gặp các khoáng vật của sắt như siderit và limonit dạng hạt nham nhở màu vàng, màu nâu bẩn.

\subsection{Các giai đoạn tạo quặng}

\subsubsection{Cấu tạo và kiến trúc quặng}

Trong các thân quặng thuộc mỏ Làng Hích thương có cấu tạo khối, mạch, xâm tán, dải, chiều dày dao động từ một vài phần milimet tới vài milimet hay cỡ centimet; hoặc cấu tạo dạng ổ đặc xít hình thành do biến chất trao đổi thay thế đá cũng như quặng được hình thành vào các giai đoạn trước. Đó là sự thay thế khoáng vật carbonat, arsenopyrit, pyrit và pyrotin bằng các khoáng vật quặng như sphalerit, galenit, chancopyrit.

Kiến trúc quặng phổ biến là hạt tự hình, cà nát, nhũ tương do phá huỷ dung dịch cứng và kiến trúc gặm mòn thay thế.

\subsubsection{Các tổ hợp cộng sinh khoáng vật}

Qua việc nghiên cứu các mẫu khoáng tướng ở khu Làng Hích, ta có thể phân chia các khoáng vật ở đây ra hai tổ hợp cộng sinh : 1) Tổ hợp sphalerit - galenit - pyrit - arsenopyrit - pyrotin là giai đoạn sau của quá trình sinh khoáng và là giai đoạn tạo quặng công nghiệp của thân quặng, thường chồng gối về không gian với giai đoạn đầu, về thời gian sinh quặng có thể liên quan với hoạt động magma xâm nhập axit kiểu Phia Bioc hoặc thậm chí là Pia Oắc. Quặng thường có kiến trúc tấm hạt tha hình, hạt nửa tự hình, thay thế gặm mòn với cấu tạo ổ đặc xít, xâm tán dày hay xâm tán mạng mạch. 2) Giai đoạn khoáng hoá nhiệt dịch - biến chất trao đổi: giai đoạn hình thành lên các tổ hợp cộng sinh khoáng vật điển hình của khoáng hoá nhiệt dịch hậu magma. Các tổ hợp cộng sinh của giai đoạn tạo khoáng này hoặc phủ chồng trực tiếp lên quặng của giai đoạn sớm tích tụ trong các đới đứt gãy (khe nứt chứa quặng).

\section{4. Đặc điểm thành phần hóa học của các khoáng vật quặng}

\subsection{Sphalerit}

Thành phần hóa học đại diện của sphalerit thuộc các khu vực khai thác khác nhau của khu mỏ Làng Hích được liệt kê trong bảng 1 .

Sphalerit của khu vực Đông Metis, Tây Metis, Hang Chùa đặc trưng có hàm lượng kẽm cao và khá ổn định, sphalerit của khu vực lò $1 \mathrm{~B}$ có mức

độ ổn định kém hơn, trong khi sphalerit của lò $1 \mathrm{~A}$

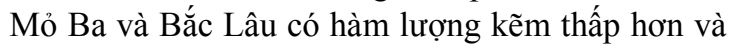
dao động trong biên độ lớn hơn (hình 2). 
Bảng 1. Thành phần hóa học đại diện của sphalerit thuộc các khu vụcc khai thác khu mỏ Làng Hích

\begin{tabular}{|c|c|c|c|c|c|c|c|c|c|}
\hline Ký hiệu mẫu & Khu vực khai thác & $\mathrm{Zn}$ & $\mathrm{Fe}$ & $\mathrm{Mn}$ & $S$ & $\mathrm{Bi}$ & $\mathrm{Cd}$ & In & Tổng \\
\hline KC.2001-1-2 & Tây Metis & 66,100 & 0,501 & 0,000 & 33,310 & 0,000 & 0,497 & 0,000 & 100,410 \\
\hline KC.2001-2-2 & Tây Metis & 67,090 & 0,292 & 0,008 & 33,480 & 0,000 & 0,477 & 0,017 & 101,370 \\
\hline KC.2001-3-1 & Tây Metis & 66,300 & 0,624 & 0,009 & 33,280 & 0,000 & 0,874 & 0,010 & 101,100 \\
\hline KC.2001-4-2 & Tây Metis & 66,000 & 0,877 & 0,013 & 33,500 & 0,014 & 0,355 & 0,000 & 100,760 \\
\hline KC.2021-1-1 & Đông Metis & 66,910 & 0,096 & 0,008 & 33,250 & 0,000 & 0,569 & 0,000 & 100,830 \\
\hline KC.2021-2-2 & Đông Metis & 67,350 & 0,049 & 0,036 & 33,360 & 0,025 & 0,360 & 0,000 & 101,180 \\
\hline KC.2021-3-1 & Đông Metis & 66,960 & 0,108 & 0,019 & 33,300 & 0,002 & 0,510 & 0,005 & 100,910 \\
\hline KC.2021-4-1 & Đông Metis & 66,410 & 0,123 & 0,010 & 33,140 & 0,000 & 0,885 & 0,001 & 100,570 \\
\hline KC.2035-1-1 & Hang Chùa & 67,100 & 0,296 & 0,023 & 33,330 & 0,013 & 0,362 & 0,002 & 101,120 \\
\hline KC.2035-2-1 & Hang Chùa & 67,380 & 0,243 & 0,013 & 33,490 & 0,038 & 0,232 & 0,000 & 101,400 \\
\hline KC.2035-3-1 & Hang Chùa & 65,610 & 1,660 & 0,023 & 33,620 & 0,026 & 0,218 & 0,001 & 101,160 \\
\hline KC.2035-41 & Hang Chùa & 66,460 & 0,154 & 0,029 & 33,370 & 0,027 & 0,275 & 0,000 & 100,310 \\
\hline KC.2050-1-1 & Bắc Lâu & 66,210 & 0,655 & 0,023 & 33,520 & 0,000 & 0,120 & 0,000 & 100,530 \\
\hline KC.2050-2-1 & Bắc Lâu & 65,240 & 0,829 & 0,027 & 33,830 & 0,037 & 0,350 & 0,000 & 100,310 \\
\hline KC,2050-3-1 & Bắc Lâu & 63,400 & 0,694 & 0,015 & 32,520 & 0,033 & 0,269 & 0,000 & 96,930 \\
\hline KC.2050-4-1 & Bắc Lâu & 66,230 & 0,238 & 0,020 & 33,790 & 0,002 & 0,585 & 0,000 & 100,870 \\
\hline KC.2068-1-1 & Mỏ Ba lò 1B & 66,550 & 0,018 & 0,027 & 33,440 & 0,003 & 0,415 & 0,000 & 100,450 \\
\hline KC.2068-2-1 & Mỏ Ba lò 1B & 66,430 & 0,104 & 0,023 & 33,460 & 0,000 & 0,483 & 0,000 & 100,500 \\
\hline KC.2068-3-1 & Mỏ Ba lò 1B & 66,340 & 0,051 & 0,000 & 33,110 & 0,012 & 0,405 & 0,000 & 99,920 \\
\hline KC.2068-4-1 & Mỏ Ba lò 1B & 65,410 & 0,079 & 0,010 & 32,970 & 0,050 & 1,560 & 0,000 & 100,080 \\
\hline KC.2090-1-1 & Mỏ Ba lò $1 \mathrm{~A}$ & 64,960 & 1,380 & 0,027 & 33,690 & 0,078 & 0,490 & 0,000 & 100,620 \\
\hline KC.2090-2-1 & Mỏ Ba lò $1 \mathrm{~A}$ & 63,690 & 2,960 & 0,021 & 33,660 & 0,027 & 0,385 & 0,005 & 100,760 \\
\hline KC.2090-3-1 & Mỏ Ba lò $1 \mathrm{~A}$ & 67,570 & 0,156 & 0,012 & 33,710 & 0,040 & 0,350 & 0,000 & 101,840 \\
\hline KC.2090-4-1 & Mỏ Ba lò 1A & 64,920 & 2,050 & 0,021 & 33,490 & 0,087 & 0,353 & 0,000 & 100,920 \\
\hline
\end{tabular}

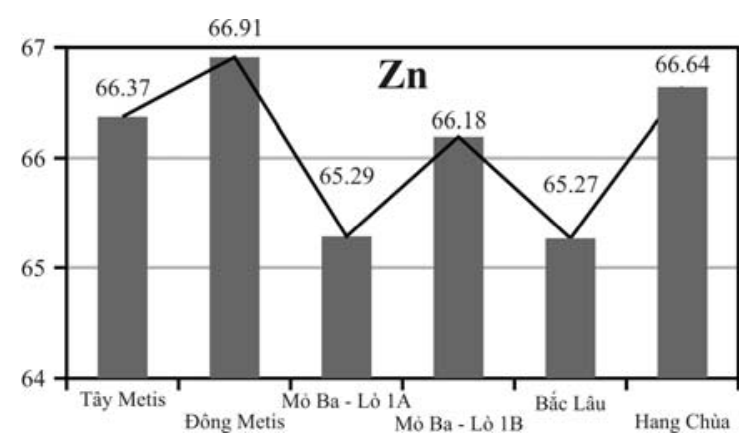

Hình 2. Biểu đồ hàm lượng kẽm các khu vực khai thác khu mỏ Làng Hích

Theo chiều tăng của hàm lượng kẽm trong sphalerit, hàm lượng sắt (hình 3) nhìn chung có khuynh hướng giảm dần. Sphalerit của khu vực Đông Metis, Hang Chùa và lò $1 \mathrm{~B}$ Mỏ $\mathrm{Ba}$ có hàm lượng sắt thấp $(0,049-0,123 \%$ tại Đông Metis, $0,154-0,296 \%$ ở Hang Chùa, cá biệt có mẫu lên đến $1,66 \%$, và $0,018-0,104 \%$ ở Lò $1 \mathrm{~B}$ mỏ $\mathrm{Ba}$ ) và ít biến động. Hàm lượng sắt của sphalerit lò $1 \mathrm{~A}$ lớn hơn, biến thiên trong khoảng rất rộng 0,156-2,96\%. Thấp hơn một chút là hàm lượng sắt tron sphlerit ở Tây Metis.

Không như sắt, hàm lượng $\mathrm{Mn}$ trong sphalerit không thấy tương quan với hàm lượng kẽm. Mn cao nhất trong sphalerit khu vực Bắc Lâu, Hang Chùa. Hàm lượng $\mathrm{Mn}$ trong sphalerit khu Đông Metis, Mỏ Ba - Lò $1 \mathrm{~B}$ có tương quan thuận với hàm lượng kẽm, trong khi $\mathrm{Mn}$ của sphalerit lò Mỏ Ba - Lò 1A, Tây Metis lại thể hiện tương quan nghịch với chiều tăng của hàm lượng kẽm (hình 3 ).

Trong sphalerit thuộc các lò khác nhau của mỏ Lang Hích đã phát hiện thấy bismuth với hàm lượng thay đổi có khi lên tới $0,09 \%$. Hàm lượng cao nhất của bismuth được tìm thấy trong sphalerit của lò $1 \mathrm{~A}$ Mỏ $\mathrm{Ba}$. Sphalerit của khu vực Bắc Lâu, Hang Chùa có hàm lượng Bi trung bình, khu Đông Metis và Tây Metis có hàm lượng $\mathrm{Bi}$ thấp nhất (hình 3). 


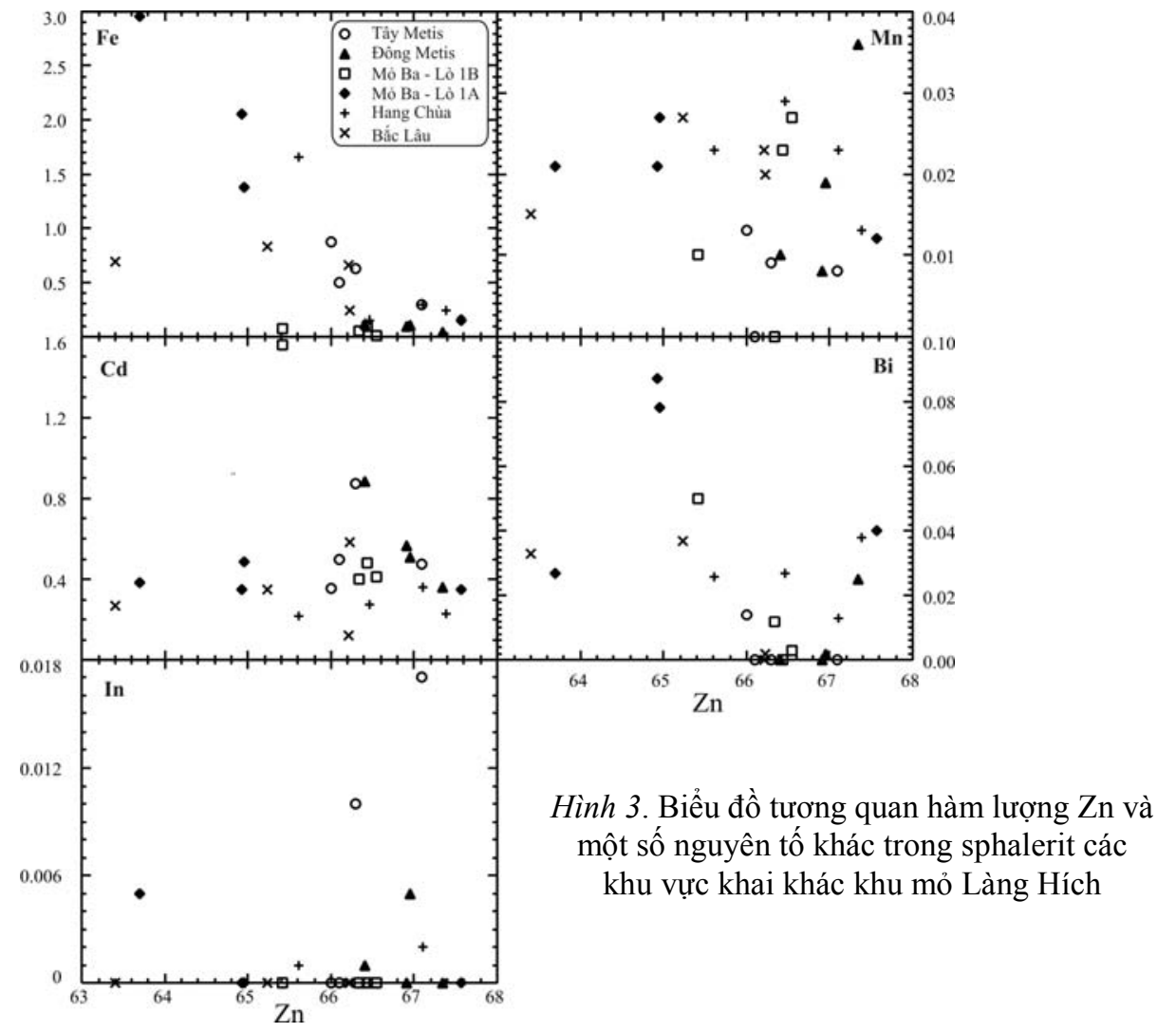

Sphalerit của tất cả các lò khai thác của mỏ Lang Hích đặc trưng bởi hàm lượng cao của Cadmi, cá biệt lên tới 1,56\% Cd ở lò $1 \mathrm{~B} \mathrm{Mỏ} \mathrm{Ba}$. Nhìn chung, hàm lượng $\mathrm{Cd}$ dao động 0,12 $0,87 \%$. Khu Đông và Tây Metis đặc trưng có hàm lượng $\mathrm{Cd}$ trong sphalerit cao nhất và giảm dần theo chiều tăng của hàm lượng kẽm. Lò $1 \mathrm{~A}, 1 \mathrm{~B} \mathrm{Mỏ} \mathrm{Ba}$ và Bắc Lâu có hàm lượng $\mathrm{Cd}$ trung bình. Sphalerit khu vực Hang Chùa có hàm lượng $\mathrm{Cd}$ thấp nhất, dao động trong khoảng 0,2-0,4 \% (hình 3).

Hàm lượng Indi trong sphalerit thay đổi trong khoảng rộng. khu vực Đông và Tây Metis đặc trưng có hàm lượng In cao nhất, lên tới 0,017 \% (hình 3).

Đối với từng khu mỏ, nhìn chung có thể thấy sphalerit khu Đông Metis và Tây Metis đặc trưng bởi hàm lượng $\mathrm{Fe}, \mathrm{Bi}$ thấp, hàm lượng $\mathrm{Mn}$, In trung bình, hàm lượng $\mathrm{Cd}$ khá cao. Sphalerit khu vực Hang Chùa, Bắc Lâu đặc trưng bởi hàm lượng $\mathrm{Bi}$ trung bình, $\mathrm{Fe}, \mathrm{In}, \mathrm{Cd}$ thấp và hàm lượng $\mathrm{Mn}$ cao. Lò $1 \mathrm{~B}$ Mỏ $\mathrm{Ba}$ đặc trưng bởi sphalerit có hàm lượng $\mathrm{Fe}$ và In thấp, hàm lượng $\mathrm{Mn}$, Bi dao động ở mức trung bình, hàm lượng $\mathrm{Cd}$ dao động mạnh, trong khi sphalerit lò $1 \mathrm{~A}$ đặc trưng bởi hàm lượng cao của $\mathrm{Fe}, \mathrm{Mn}$ và $\mathrm{Bi}$, hàm lượng In thấp, hàm lượng $\mathrm{Cd}$ trung bình.

\subsection{Galenit}

Thành phần hóa học đại diện của galenit thuộc các khu vực khai thác khác nhau được liệt kê trong bảng 2.

Galenit thuộc các lò khác nhau đặc trưng bởi hàm lượng chì khá đồng nhất, trong đó cao nhất là hàm lượng chì trong galenit ở Tây Metis, Đông Metis và Bắc Lâu có hàm lượng trung bình, thấp nhất là ở Mỏ Ba- Lò 1B (hình 4). Trong galenit, hàm lượng bạc của khu vưc Đông Metis và Mỏ $\mathrm{Ba}$ - Lò 1 A khá cao, lên tới $0,09 \%$. Galenit của khu vực Bắc Lâu có hàm lượng bạc thấp hơn, còn galenit của Mỏ Ba - Lò $1 \mathrm{~B}$ dao động $0-0,07 \%$ (hinh 5).

Galenit trong các lò khác khau thuộc khu vực Làng Hích đặc trưng có hàm lượng antimon dao động trong khoảng $0,01-0,5 \%$, cá biệt trong 1 mẫu galenit lò $1 \mathrm{~A} \mathrm{Mỏ} \mathrm{Ba}$, hàm lượng antimon lên tới $1,01 \%$. Nhìn chung, hàm lượng antimon lò $1 \mathrm{~B}$ Mỏ Ba cao hơn so với các lò khác (hình 5). 
Bảng 2. Thành phần hóa học đại diện của galenit thuộc các khu vực khai thác khu mỏ Làng Hích

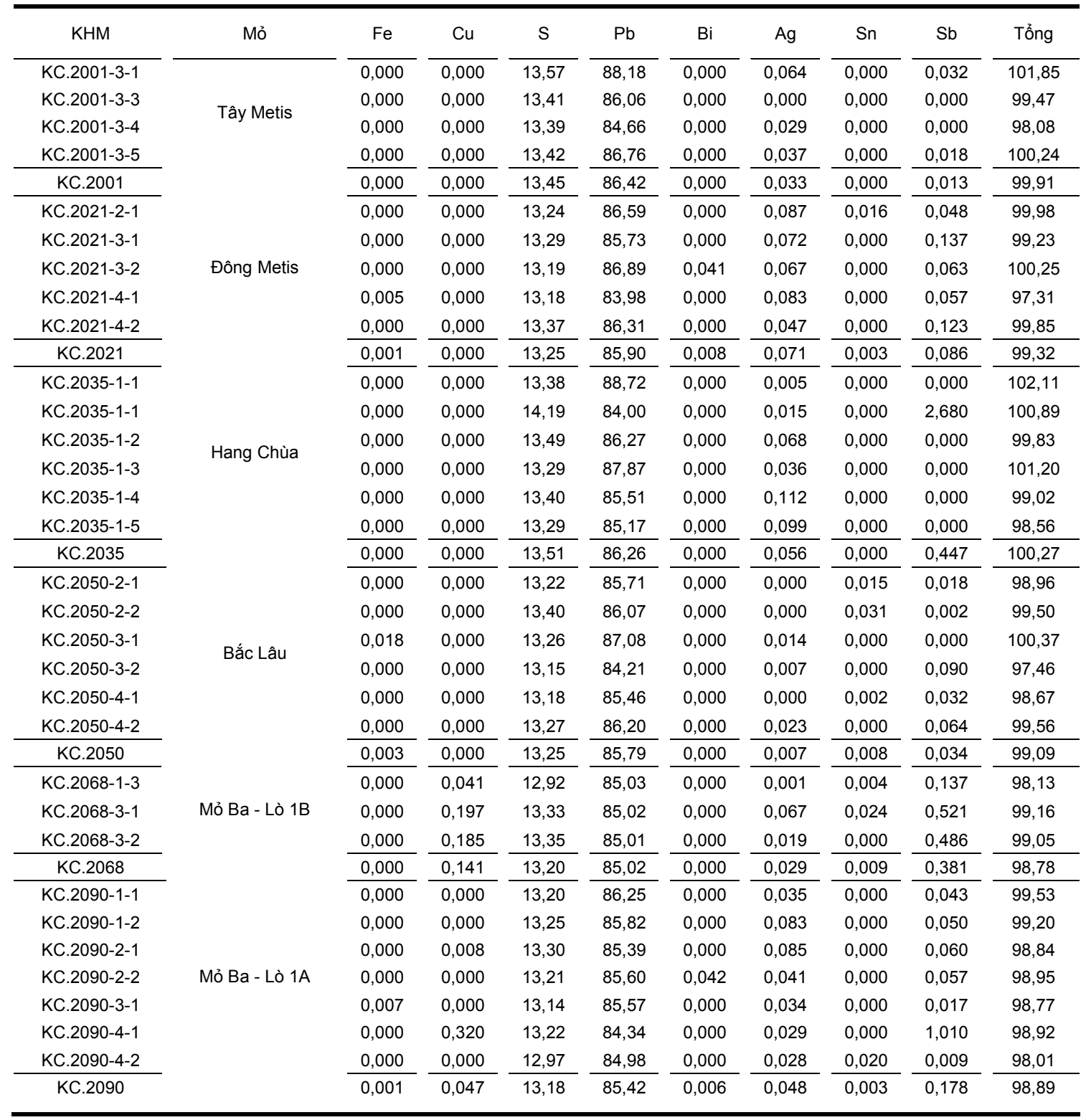

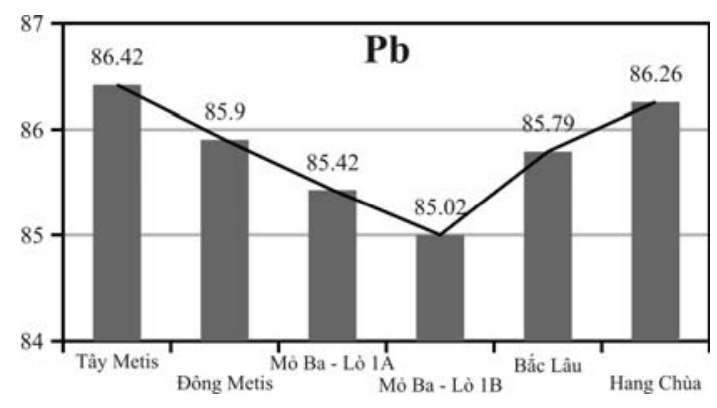

$\leftarrow$ Hình 4. Biểu đồ hàm lượng $\mathrm{Pb}(\% \mathrm{tl})$ tại các

khu vực khác nhau của khu mỏ Làng Hích 


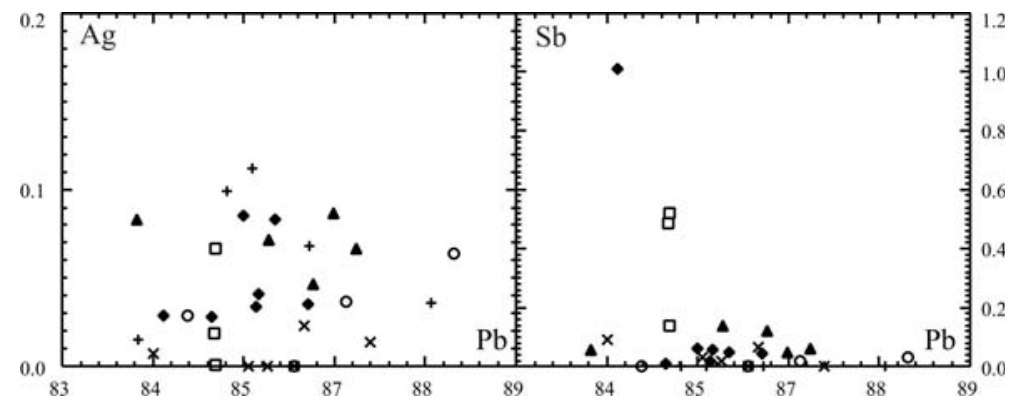

Hình 5. Biểu đồ tương quan hàm lượng $\mathrm{Pb}$ và $\mathrm{Ag}, \mathrm{Sb}$ trong sphalerit các khu vực khai khác khu mỏ Làng Hích. Ký hiệu tương tự như hình 3

Bảng 3. Thành phần hóa học đại diện của pyrit thuộc Mỏ Ba - Lò $1 \mathrm{~A}$ khu mỏ Làng Hích

\begin{tabular}{|c|c|c|c|c|c|c|c|c|c|}
\hline $\mathrm{KHM}$ & $\mathrm{Fe}$ & Co & As & $S$ & $\mathrm{Ni}$ & $\mathrm{Cu}$ & $\mathrm{Se}$ & Mo & Tổng \\
\hline KC.2090-3-1 & 45,750 & 0,039 & 0,000 & 53,680 & 0,061 & 0,039 & 0,000 & 0,000 & 99,570 \\
\hline KC.2090-3-1 & 45,960 & 0,001 & 0,000 & 53,250 & 0,202 & 0,043 & 0,000 & 0,000 & 99,460 \\
\hline
\end{tabular}

Các nghiên cứu về thành phần của galenit thuộc các lò khác nhau cho thấy chúng có chứa một hàm lượng bạc khá cao, có thể thu hồi được. Ngoài ra, antimon cũng được tìm thấy trong thành phần của galenit. Các nguyên tố này tồn tại ở dạng nào (thay thế đồng hình hoặc là những bao thể khoáng vật nhỏ trong galenit) thì cũng cần phải có những nghiên cứu chi tiết hơn.

\subsection{Pyrit}

Thành phần hóa học đại diện của pyrit thuộc Mỏ Ba - Lò $1 \mathrm{~A}$ được liệt kê trong bảng 3. Pyrit khu vực này đặc trưng có hàm lượng $\mathrm{Fe}$ và $\mathrm{S}$ tương đồng với pyrit điển hình. Trong thành phần của pyrit hàm lượng $\mathrm{Co}$ phân tích được lên tới $0,04 \%$, Ni $0,2 \%, \mathrm{Cu} 0,04 \%$.

\subsection{Các khoáng vật nhóm tetraedrit}

Trong quặng chì kẽm của khu vực lò Tây Metis đã phát hiện thấy sự hiện diện của các khoáng vật nhóm tetraedrit (bảng 4). Theo thành phần hóa học, chúng tương ứng với giraudit hoặc freibergit với hàm lượng bạc dao động từ 17,8-20,04\% (bảng 4). So với các khoáng vật chuẩn của nhóm này, tetraedrit của khu vực Làng Hích có hàm lượng sắt thấp hơn, song hàm lượng antimony trung bình từ 26,3 đến $26,9 \%$.

\subsection{Bournonit ( $\mathrm{PbCuSbS}$ )}

Bournonit được tìm thấy ở khu vực $\mathrm{Mỏ} \mathrm{Ba}$. So với bournonit thông thường, bournonit của khu vực Mỏ Ba đặc trưng có hàm lượng antimony thấp hơn, $14,56-21,9 \%$, hàm lượng As 0,26-4,9\%. Hàm lượng Bi trong chúng lên tới 0,05 \% (bảng 5).

Bảng 4. Thành phần hóa học đại diện của các khoáng vật nhóm tetrahedrit Tây Metis

\begin{tabular}{|c|c|c|c|c|c|c|c|c|c|}
\hline $\mathrm{KHM}$ & $\mathrm{Cu}$ & $\mathrm{Sb}$ & $\mathrm{Zn}$ & $\mathrm{Fe}$ & $\mathrm{Ag}$ & $S$ & As & $\mathrm{Pb}$ & Tổng \\
\hline KC-2003-1 & 23,97 & 26,79 & 6,65 & 0,18 & 18,26 & 22,98 & 0,00 & 0,16 & 98,99 \\
\hline KC-2003-2 & 24,43 & 26,34 & 6,77 & 0,19 & 17,81 & 22,97 & 0,00 & 0,15 & 98,65 \\
\hline KC-2003-3 & 24,36 & 26,65 & 6,74 & 0,23 & 18,03 & 22,99 & 0,00 & 0,15 & 99,16 \\
\hline KC-2003-4 & 24,50 & 26,28 & 6,66 & 0,19 & 18,03 & 23,02 & 0,00 & 0,11 & 98,79 \\
\hline KC-2003-5 & 23,24 & 26,34 & 6,51 & 0,19 & 20,04 & 22,63 & 0,00 & 0,15 & 99,11 \\
\hline Freibergit* & 11,86 & 18,93 & & 3,47 & 40,25 & 21,60 & 3,88 & & \\
\hline Tetrahedrit* & 34,80 & 29,64 & & 10,20 & & 25,37 & & & \\
\hline Argentotennantit* & 8,55 & 6,56 & 5,28 & 1,50 & 43,56 & 22,44 & 12,1 & & \\
\hline
\end{tabular}

* Tham khảo từ www.webmineral.com 
Bảng 5. Thành phần hóa học của Bournonit khu vục Mỏ Ba - Lò 1B

\begin{tabular}{|c|c|c|c|c|c|c|c|c|}
\hline KHM & $\mathrm{Cu}$ & $\mathrm{Zn}$ & As & $S$ & $\mathrm{~Pb}$ & $\mathrm{Bi}$ & $\mathrm{Sb}$ & Tổng \\
\hline KC.2068-1-1 & 13,110 & 0,000 & 0,584 & 19,540 & 42,490 & 0,033 & 20,940 & 96,700 \\
\hline KC.2068-2-1 & 13,070 & 0,000 & 0,284 & 19,530 & 42,460 & 0,053 & 21,810 & 97,210 \\
\hline KC.2068-4-1 & 13,480 & 0,178 & 4,910 & 19,960 & 43,840 & 0,000 & 14,560 & 96,940 \\
\hline KC.2068-4-2 & 13,120 & 0,010 & 0,263 & 19,680 & 41,770 & 0,043 & 21,630 & 96,520 \\
\hline Bournonite* & 13,00 & & & 19,68 & 42,40 & & 24,91 & \\
\hline
\end{tabular}

\section{Thành phần hóa quặng}

Thành phần hóa quặng đại diện được phân tích bằng phương pháp Huỳnh quang Rơnghen tại Viện
Địa chất - Viện Khoa học và Công nghệ Việt Nam. Nhìn chung hàm lượng kẽm của quặng 3,65$28,1 \%$, chì 2,23-13,9\%, đặc biệt hàm lượng $\mathrm{Cd}$ trong chúng luôn cao, lên tới 0,03-0,25\% (bảng 6).

Bảng 6. Thành phần hóa quặng tổng của quặng kẽm-chì khu mỏ Làng Hích

\begin{tabular}{|c|c|c|c|c|c|c|c|c|c|}
\hline $\mathrm{KHM}$ & KC.2001 & KC.2002 & KC. 2007 & KC.2016 & KC.2020 & KC.2056 & KC.2084 & KC.2085 & KC.2090 \\
\hline Khu vực & $\begin{array}{l}\text { Tây } \\
\text { Metis }\end{array}$ & $\begin{array}{l}\text { Tây } \\
\text { Metis }\end{array}$ & $\begin{array}{l}\text { Tây } \\
\text { Metis }\end{array}$ & $\begin{array}{l}\text { Đông } \\
\text { Metis }\end{array}$ & $\begin{array}{l}\text { Đông } \\
\text { Metis }\end{array}$ & $\begin{array}{l}\text { Bắc } \\
\text { Lâu }\end{array}$ & $\begin{array}{l}\text { Mỏ Ba } \\
\text { Lò } 1 \mathrm{~A}\end{array}$ & $\begin{array}{l}\text { Mỏ Ba } \\
\text { Lò } 1 \mathrm{~A}\end{array}$ & $\begin{array}{l}\text { Mỏ Ba } \\
\text { Lò 1A }\end{array}$ \\
\hline Si & & 0,07 & 0,13 & & & 5,09 & 1,16 & & 7,82 \\
\hline $\mathrm{Ti}$ & & & & 0,03 & & 0,05 & 0,03 & 0,03 & 0,10 \\
\hline $\mathrm{Al}$ & 0,23 & 0,18 & 0,29 & 0,64 & 0,61 & 1,92 & 0,86 & 0,73 & 4,85 \\
\hline $\mathrm{Fe}$ & 0,89 & 1,46 & 0,68 & 1,41 & 0,19 & 1,12 & 0,42 & 0,36 & 1,32 \\
\hline $\mathrm{Mg}$ & 0,85 & 1,86 & 1,22 & 1,96 & 0,11 & 1,67 & 1,82 & 2,54 & 1,61 \\
\hline $\mathrm{Mn}$ & 0,02 & 0,02 & 0,02 & 0,07 & & 0,28 & 0,04 & 0,04 & 0,14 \\
\hline $\mathrm{Ca}$ & 2,27 & 4,46 & 4,61 & 36,04 & 1,62 & 25,52 & 46,98 & 36,96 & 5,64 \\
\hline $\mathrm{Na}$ & 3,98 & 4,67 & 3,91 & 0,07 & 3,85 & 0,33 & & & 2,23 \\
\hline K & 0,01 & 0,00 & 0,01 & 0,19 & 0,11 & 0,80 & 0,43 & 0,28 & 1,51 \\
\hline$P$ & 10,08 & & & 14,33 & 16,76 & & & 3,66 & \\
\hline $\mathrm{O}$ & 30,80 & 32,60 & 31,60 & 27,80 & 30,80 & 31,90 & 24,60 & 27,30 & 37,70 \\
\hline $\mathrm{Cu}$ & & 0,01 & 0,02 & 0,02 & 0,05 & 0,01 & & 0,06 & 0,02 \\
\hline $\mathrm{Pb}$ & 13,24 & 5,61 & 8,90 & 4,27 & 13,39 & 4,86 & 2,23 & 3,51 & \\
\hline $\mathrm{Zn}$ & 27,09 & 26,57 & 28,10 & 10,25 & 24,93 & 16,92 & 3,65 & 14,31 & 20,13 \\
\hline $\mathrm{Cd}$ & 0,23 & 0,18 & 0,25 & 0,09 & 0,25 & 0,08 & 0,03 & 0,09 & 0,12 \\
\hline $\mathrm{Rb}$ & 0,06 & & & 0,70 & 0,48 & & & 0,81 & \\
\hline $\mathrm{Sr}$ & & & & 0,04 & & 0,01 & 0,04 & 0,03 & \\
\hline S & & 13,47 & 12,87 & & & 5,17 & 0,81 & & 9,42 \\
\hline
\end{tabular}

\section{Nhận định và kết luận}

Qua nghiên cứu các đặc điểm quặng hóa và khoáng vật học của các khu vực khai thác khu mỏ Làng Hích, có thể thấy :

(1) Tồn tại hai tổ hợp cộng sinh khoáng vật theo thứ tự thành tạo pyrit-galenit-sphalerit (khu vực Metis, Mỏ Ba) hoặc galenit-sphalerit (khu vực Bắc Lâu và Hang Chùa).

(2) Sphalerit khu Đông Metis và Tây Metis đặc trưng bởi hàm lượng $\mathrm{Fe}, \mathrm{Bi}$ thấp, hàm lượng $\mathrm{Mn}$, In trung bình, hàm lượng $\mathrm{Cd}$ khá cao. Sphalerit khu vực Hang Chùa, Bắc Lâu đặc trưng bởi hàm lượng $\mathrm{Bi}$ trung bình, $\mathrm{Fe}, \mathrm{In}, \mathrm{Cd}$ thấp và hàm lượng $\mathrm{Mn}$ cao. Mỏ Ba - Lò $1 \mathrm{~B}$ đặc trưng bởi sphalerit có hàm lượng $\mathrm{Fe}$ và In thấp, hàm lượng $\mathrm{Mn}, \mathrm{Bi}$ dao động ở mức trung bình, hàm lượng $\mathrm{Cd}$ dao động mạnh, trong khi sphalerit lò $1 \mathrm{~A}$ đặc trưng bởi hàm lượng cao của $\mathrm{Fe}, \mathrm{Mn}$ và $\mathrm{Bi}$, hàm lượng In thấp, hàm lượng $\mathrm{Cd}$ trung bình.

(3) Galenit thuộc các lò khác nhau cho thấy chúng có chứa một hàm lượng bạc khá cao, có thể thu hồi được. Ngoài ra, antimon cũng được tìm thấy trong thành phần của galenit. Các nguyên tố này tồn tại ở dạng nào (thay thế đồng hình hoặc là những bao thể khoáng vật nhỏ trong galenit) thì cũng cần phải có những nghiên cứu chi tiết hơn.

(4) Ngoài ra, các nghiên cứu còn chỉ ra sự tồn tại của các khoáng vật chứa bạc của nhóm 
tetraedrit (Tây Metis) và chứa antimon (bournonit) (Mỏ Ba - Lò 1B). Về mức độ phổ biến và có thể thu hồi được của các khoáng vật này hay không, cần có những nghiên cứu chi tiết hơn để xác định triển vọng của các khoáng vật này.

(5) Thành phần hóa quặng đơn giản, ngoài hàm lượng cao của $\mathrm{Zn}$ và $\mathrm{Pb}, \mathrm{Cd}$ ở đây cũng có hàm lượng cao và có thể tiến hành đánh giá chi tiết cho việc thu hồi.

Các kết quả nghiên cứu khoáng tướng, trọng sa nhân tạo, kết quả phân tích EPMA-SEM trên khoáng vật, XRF được lấy từ kết quả nghiên cứu của Đề tài KC.08.24/06-10.

\section{TÀI LIÊU DÃ̃N}

[1] Dovjkov A.E., 1965: Địa chất miền Bắc Việt Nam. Nxb KH và KT, Hà Nội.

[2] Gospodinov G.R., Nguyễn Nghiêm Minh, Nguyễn Văn hoc, 1987: Về các nguyên tố có ích đi kèm trong các thành hệ quặng chì-kẽm ở Việt Nam. TC Địa chất, A 180, tr 14-19.

[3] Nguyễn Văn Nhân và nnk, 1974: Đặc điểm quặng hóa một số mỏ chì - kẽm, antimoan vùng đông Bắc Việt Nam. Lưu trữ, Viện TTTL Địa chất. Cục Địa chất và Khoáng sản . Hà Nội.
[4] Nguyễn Văn Nhân, 1977: Đặc điểm quặng hoá chì - kẽm Đông Bắc Việt Nam. Lưu trữ Viện TTTL Địa chất. Hà Nội.

[5] Nguyen Van Nhan, 1995: Polymetallic ore formatioms in Vietnam. J. of Geology (Vietnam), B 5, pp. 389-393.

[6] Nguyên Văn Nhân, 1996: Thành hệ quặng nội sinh ở Việt Nam. TC Địa chất. A234.

[7] Nguyễn Văn Nhân, 2000: Một số đặc điểm của sphalerit trong các mỏ và tụ khoáng chì - kẽm thuộc các kiểu khác nhau và ý nghĩa thực tiễn của chúng. Tc. Địa chất, loạt $\mathrm{A}$, số dành cho Khoa Địa chất, Trường ĐH KHTN - ĐHQG HN.

[8] Reynolds N.A., 1995: The Cho Don-Cho Dien $\mathrm{Zn}-\mathrm{Pb}$ district and setting of carbonate-hosted base metal mineralization in Devonian of Northern Vietnam, J. of Geology (Vietnam), B 5, pp.433-434.

[9] Trần Văn Trị và nnk, 1998: Tài nguyên khoáng sản Việt Nam, tập III. Viện Địa chất Khoáng sản, Cục Địa chất và Khoáng sản. Hà Nội. $214 \mathrm{tr}$

[10] Trần Văn Trị (chủ biên) và nnk, 2000: Tài nguyên khoáng sản Việt Nam. Cục Địa chất và khoáng sản Việt Nam, Bộ công nghiệp nặng. Hà Nội.

\section{SUMMARY}

\section{Chemical and mineralogical characteristics of $\mathrm{Zn}-\mathrm{Pb}$ ores in Lang Hich area}

Lang Hich ore deposit consisting of 6 mining places (West Metis, East Metis, Hang Chua, Bac Lau, Mo Ba - 1A oven, Mo Ba - 1B) was discovered in 1905 and has been exploited since 1913. Anually, the mine have been exploited $\sim 20000 \mathrm{~T}$, inspite of lacking detail investigation in mineralogy and chemistry of ores.

Two mineral assemblages have been clafsified in Lang Hich deposit as followed : 1) pyrite-galenite-sphalerite (Metis, Mo Ba), 2) galenite-sphalerite (Bac Lau, Hang Chua). Basically, sphalerites, have low Fe, In contents ; $\mathrm{Bi}$ is medium ; Mn and $\mathrm{Cd}$ is high, especially, $\mathrm{Cd}$ have very high content. While galenite contains $\mathrm{Ag}$ at economical value, besides, the presence of $\mathrm{Sb}$ is recored. Other investigation also shows the existing of tetraedrite group, an Ag bearing mineral group, and bournonite, a $\mathrm{Sb}$ bearing mineral. 